\title{
Key Performance Indicators (KPIs) in the Change Management of Public Administration
}

\author{
Adisa Bala, PhD Candidate \\ Prof. Dr. Andrea Koxhaj \\ Faculty of Economy, Tirana University
}

doi: 10.19044/esj.2017.v13n4p278 URL:http://dx.doi.org/10.19044/esj.2017.v13n4p278

\begin{abstract}
This paper is part of my progress work within the research topic focused on change management process in the public administration. The aim will be describing some specific and crucial milestones of this challenging process. Change is inevitable and a continuous process if we want to improve our public administration. If we refer to change management the first element we cross through is the concept of a new system, regulation, structure ect. While introducing the change, we have to take care not only to the context, to the typology of the process, its factors and actors. The most important is considering the successful results in the mean of facing and applying it. But how can we define this success in the terms of public administration? Which can be some measurements to use in order to evaluate the performance of change management? How is performance management linked to an effective, efficient or a viable change management? I will try to answer to these concerns, through explaining further the general key indicators of determining performance in public administration in order to lead a successful process of managing the change.
\end{abstract}

Keywords: Public administration/ key performance indicators/change management

\section{Introduction}

An organization, institution ${ }^{76}$ either it is public or private adopt different performance management systems. Public sector is recently under pressure not only to develop new administrative reforms, but exclusively to match its priorities to the needs of citizens. More and more the focus is shifting to accountability as well as adopting enterprise management

\footnotetext{
${ }^{76}$ In order to be more consistent during the study, we are going to use terms like public organization, public institution, public agencies or just governments as identifying concepts of public sector or vice versa.
} 
methodologies. Without stopping to the overall known importance of performance in every step activity, I want to describe the other part of the coin, which is how this performance changes by changing the organization. Performance management has gradually become an integral part of modern governance arrangements (Pollitt and Bouckaert 2004). These systems monitor the achievement of the organizational goals, monitor their progress and help to make the necessary adjustments towards. In my case the goal is experiencing an organizational change by managing and facing it successfully. So I have to address some performance indicators of the public sector in order to be followed during this process. Obviously there is no formula to figure out some stable or unique indicators to all kind of public sector organizations, because they vary from state to state, from government to government depending on many factors. As much as we concentrate on a small, exclusive part of public sector as much specific become the indicators. However there are some general tips to be respected, which are the backbone of public sector performance.

\section{Performance measurement and its KPIs}

Performance management in public administration has had a long ascent and probably has a long road ahead. As we will explain below performance indicators are intended to link managers and employees priorities with those of the whole organization with the resources they dispose. From the review of performance management literature, the basic assumptions and components of performance management are similar despite differences in vocabulary or even level of system implementation. "A common assumption across this literature is that management matters to performance and effectiveness, and that performance is the ultimate goal of public management systems and actions," (Moynihan and Pandey, 2005) I want also to refer to a very comprehensive assumption “...an ongoing, systematic approach to improving results through evidence-based decisionmaking, continuous organizational learning, and a focus on accountability for performance. Performance management is integrated into all aspects of an organization's management and policy-making processes and transforms an organization's practices so that they are focused on achieving improved results for the public.” (Mucha, 2011)

Key Performance Indicators, also known as KPI or Key Success Indicators (KSI), help an organization define and measure progress toward organizational goals. Once an organization has analyzed its mission, identified all its stakeholders, and defined its goals, it needs a way to measure progress toward those goals. Key Performance Indicators are those measurements. 
Key Performance Indicators are quantifiable measurements that reflect the critical success factors of an organization. They will differ depending on the organization. Whatever Key Performance Indicators are selected, they must reflect the organization's goals, they must be key to its success. Key Performance Indicators usually are long-term considerations. The definition of what they are and how they are measured do not change often. Key Performance Indicators reflect the organizational goals. If we refer to a public institution which is holding financial, social or cultural goals to fulfill their mission by delivering a public service, we can say that these indicators must be the platform to be followed in order to achieve these goals. Key Performance Indicators must be quantifiable (measurable). If a KPI is going to be of any value, there must be a way to accurately define and measure it. As in private sector, also the public organizations can put some numeric indicators to measure their efficiency and electivity in public service, especially those kinds of public agencies, whose activity is directly related to the public.

Now turning back to the overall aim of my study i.e. change management, measurement should be considered during the planning of change before any action is undertaken. The approach to performance management is changing as government is making efforts to provide greater transparency, 'openness' and accountability. In this time of change and drive for greater efficiency, performance management is firmly under the spotlight. As public priorities are changing, specifically in the face of EU integration reforms, pressure will also be not just managing this, but identifying the correct new measurements. Measurement helps in multiple ways. It should motivate employees to perform desired new activities. Measurement also should provide guidance toward goal achievement and alert managers to the risk of resistance. To assure that it performs this function; measures should be taken frequently and at critical milestones in the change process.

As H. James Harrington developed "Measurement is the first step that leads to control and eventually to improvement. If you can't measure something, you can't understand it. If you can't understand it, you can't control it. If you can't control it, you can't improve it “. All measures should be transparent and make sense to those who will be held accountable for them. However establishing few KPIs isn't the solution or at least can't be until we are not sure if the change of one KPI will bring effect to the next one, so we have to consider this fact while electing for the best comprehensive indicators in an organization. 


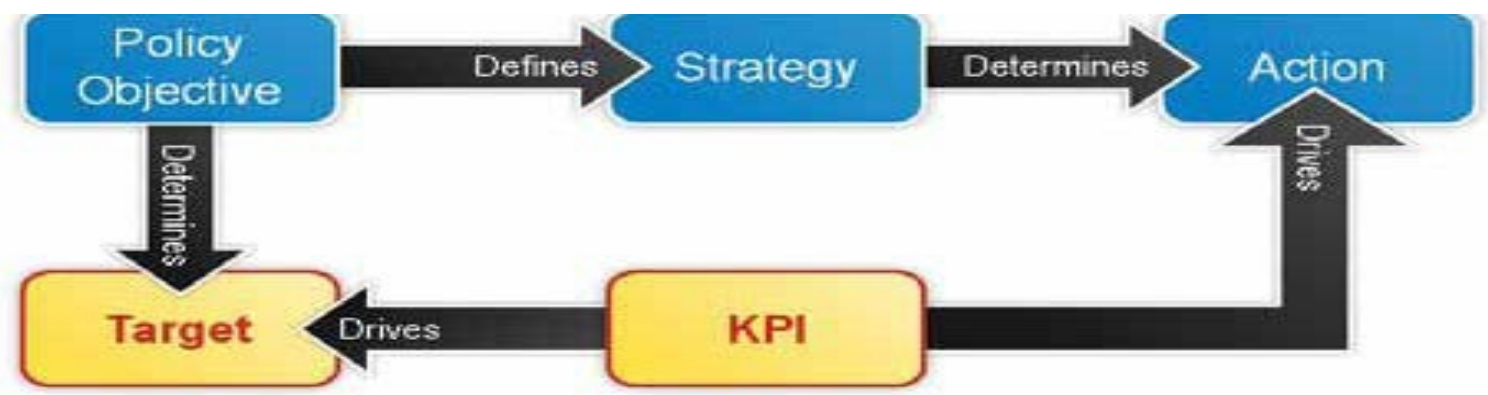

Fig.1 The relationship between KPIs, policy objectives and targets ${ }^{77}$

As seen in the figure showed above, KPI is the way through which a government unit or department has to pass through in order to realize their targets.KPI essentially drives the whole action by providing a framework which ensures the achievement of policy objectives by the strategies. It is important to be careful when describing them because not to mix or confuse with objectives or targets. They just measure the outcomes of strategy delivery. Performance management is improved because the use of these indicators has a high impact on the future performance of the sector and ensures a long term success of the change made. Trying to be more concrete, we can describe KPIs like:

- Aligned with the organization/institution/department/unit strategy

- Can be financial, on financial or monitored basically at senior level of the unit

- Exclusively has a clear owner at top management, which means that is accountable for it

- Less indicators we put the more easier to follow they can be When introducing change with a certain strategy firstly we have to set a clear vision and mission which is the paramount of establishing indicators for the performance measurement of its implementation. Actually we can refer as a significant example the changes happening to the system of civil service in the human resources management by the introduction of the new reform. They were identified with the aims to ensure a stable civil service, professional, merit-based, moral integrity and political impartiality. To achieve these targets many new laws and guidelines are being implemented which must be driven by these indicators we are trying to design. So a KPI this time can be the increasing number of the experienced servants or another type can be the reducing number of inefficient structures. In this way the performance of the reform can be very easily measured and managed frequently.

${ }^{77}$ www.sas.com 


\section{Paradoxes of performance measurements}

Recently, evaluative research has uncovered some paradoxes in the current discussion about trying to improve the management.

Not everything is countable

Albert Einstein's office at Princeton University had a sign stating, 'Not everything that counts can be counted, and not everything that can be counted counts'. We mentioned above that manage performance by KPI we should establish in that form that they can be measured, but it is forgotten that KPI are not that important, because they are not outcomes or key results after all. Relating to the change process in public sector, what is important is the success after implementing it, so the result is what matters. It does not matter how many strategies are being used (which is an output), public administration and government want efficiency in management (which is an outcome). Therefore, performance measurement should primarily focus on outcomes. Here derives the paradox, outcomes are in many instances very hard to count. We know that what is measured gets attention, but we also know that many important dimensions are immeasurable.

Skepticism towards professionals

Performance management doctrine has an ambiguous attitude towards expertise and professionals. On the one hand, professionals are the key to better performance. In fact, the NPM phrase 'let managers manage' reflects confidence in the professionalism of managers (Kettl 1997). So it is expected that these individuals be the leaders of the change and in the same time the monitors of their team. On the other hand, performance management systems often express a certain amount of distrust in professionals and all this is seen in the moment when their performance fall back on control and audit, which in many times doubts on their results by unnecessary verification.

\section{CONCLUSION}

Change is always a challenging concept for everyone, despite his position as an agent of change or just an applicator of change. People are naturally resistant to change. This is why in this situation should begin with small changes, which are also easily measurable. The common rule when selecting a KPI is recognizing that there is no 'one size fits all'.

It is clear that public sector managers have additional challenges when it comes to KPI setting. These challenges mean the effective and successful communication of the role of performance management, is more important than ever. Measurement through Key Performance Indicators (KPI) can provide an important and necessary calibration of performance assuming that coordination exists between the organization's mission, structure, processes and performance measures. Without this alignment, it's 
unclear that the "right" KPIs are being measured. Communication and understanding are key so that organizations comprehend the relevance of the KPIs and how and when they will be monitored. Public sector managers should focus on communication of the KPIs in an effective manner and quantifying performance in meaningful ways if they want to demonstrate success. Every government organization is different and best practices should be followed to suit different ways of adopting change in order to be successful.

\section{References :}

1. Cokins,G.(2011) Designing KPIs for improved Public Sector Performance, ,SAS Public Sector

2. Harbour, Jerry L. (1997). The Basics of Performance Measurement. Portland, Oregon: Productivity Press.

3. Liou, Kuotsai Tom and Ronnie Korosec (2009). "Implementing Organizational Reform Strategies in State Governments.” Public Administration Quarterly, 33(3)

4. Mandell, M. and Keast, R., (2008) Introduction. Public Management Review 10 (6)

5. Mucha, Michael J. ,Performance Management Self Evaluation: While Governments Should Continually Evaluate and Look for Opportunities to Improve Their Services, the Same Can Be Done with Their Overall Performance Management Approach, Government Finance Review, Vol. 27, No. 3 , June 2011

6. Moynihan, D. P., (2008) The Dynamics of Performance Management: Constructing Information and Reform. Washington D.C.: Georgetown University Press.

7. O’Neill, Robert J. (2008). “A Roadmap to Measuring Performance.” Government Finance Review, 24(3)

8. Wouter van Dooren and Nick Thijs, Paradoxes of improving performance management

9. (systems) in public administration, Eipascope 2010 (2)

10. www.kpilibrary.com

11. www.elpa.eu

12. www.sas.com 